\title{
A New Method for Estimating of Patient Effective Dose in Computed Tomography Based on Body Mass Index: Performance of the Method in Abdo- men-Pelvic Examination
}

\author{
Mohammad Hossein Jamshidi', Mohammad Reza Deevband², Mohammad Javad Tahmasebi Birgani ${ }^{3,4}$, Ali \\ Yadollahpour $^{3}$ and Morteza Tahmasebi ${ }^{5}$
}

${ }^{1}$ Department of Radiologic Technology, Faculty of Paramedicine, Ahvaz Jundishapur University of Medical Sciences, Ahvaz, Iran

${ }^{2}$ Department of Medical Physics and Biomedical engineering, Shahid-Beheshti University of Medical Sciences, Iran

${ }^{3}$ Faculty of Medicine, Ahvaz Jundishapur University of Medical Sciences, Iran

${ }^{4}$ Department of Radiation Therapy, Golestan Hospital, Ahvaz Jundishapur University of Medical Sciences, Iran

${ }^{5}$ Department of Radiology, Golestan Hospital, Ahvaz Jundishapur University of Medical Sciences, Iran

Received date: December 16, 2017; Published date: January 24, 2018

*Corresponding author: Mohammad Reza Deevband,Department of Medical Physics and Biomedical engineering, Shahid-Beheshti University of Medical Sciences, Tehran, Iran, Email: mdeevband@sbmu.ac.ir

\begin{abstract}
Background and Objective: Along with all the benefits that CT-scan has, the dose is much higher than other radiology procedures. The nobility of the present scientific study was to investigate how the introduction of MDCT scanners and patient-size-dependent imaging protocols have affected patient doses.
\end{abstract}

Materials and Methods: Demographic data of each patient were recorded as well as data from a CT scan of the abdomen and pelvic of 52 patients were studied. For assessment of patient and effective doses, the information related to the scan in ImPACT software was applied. The results are analyzed and regression was used in order to examine the relation between the results of the scan data in MATLAB environment.

Findings: The research findings showed that the received dose to the most patients is the same as determined by the ICRP103. An average of the effective dose was less than predicted amount by ICRP103. In addition, to estimate the effective dose of the body, according to the patient's BMI, an equation was obtained that the results from this equation are corresponded to the calculated dose by Impact (R2>0.95). In addition, the method was proposed to predict the parameters of $\mathrm{mA}$ effand DLP resulted from the related scan.

Conclusion: According to the results of this study, authors proposed a good alternative to estimate the effective dose according to BM instead of ImPACT calculations for scanners and scanning conditions as well as a method to predict the effective dose by using the parameters of the CT system and BMI without being radiated on the patients.

Keywords: CT; Patient's dose; Effective dose; Impact

\section{Introduction}

The use of ionizing radiation in medical imaging, including computed tomography (CT) provides valuable diagnostic information that undoubtedly has been beneficial for patients [1]. Studies also show that the CT scan increased by $70 \%$ between years 1998 and 2003 [2,3]. The CT Provide high quality images, especially in low-contrast soft tissue, are another advantage. Along with all the benefits that the CT scans which have, the patient dose of this modality is much greater than other methods [4]. As a result, medical imaging community must ensure that the benefits of radiological examination for each patient are higher than related risks $[5,6]$. Although the CT has a small percentage of radiological examination, but it has a large contribution on the exposure to the community. However the last few years, various techniques and patient based strategies have been developed to reduce the radiation dose delivered during CT examinations [7]. Studies have shown that the CT examination in Europe and America are included $4 \%$ and $11 \%$ of total diagnostic examination respectively, but the total dose the population of this method were $40 \%$ and $67 \%$, which in turn shows this method has the top share in population exposure [8-10]. 
The utilization of CT examinations and the amount of radiation used to perform specific examinations is of increasing concern to the medical imaging community, regulatory bodies, as well as the general public $[11,12]$. It is therefore important that the medical imaging community have practical tools to permit the dose quantities currently provided by commercial CT scanners (i.e., dose length product DLP) to be converted into a Concept metric that is meaningful and understandable $[13,14]$. The volume computed tomographic dose index [CTDIvol] will be increased by increasing in $\mathrm{mA}$, which is an indicator that this parameter's value determines the relative intensities of radiation that reaches the patient [15]. The dose length product [DLP]can be used to quantify the total amount of radiation received by patients during a given scan [11]. The effective dose is a proper dosimetry parameter for estimating the ionizing radiation hazards [16]. The DLP is proportional to effective dose [ED], which is a measure of radiation risk $[17,18]$ and it is related to the patient risk. Establishment of the related diagnostic reference values for a given type of examination, help to ensure patient doses at CT are met as low as reasonably achievable [19]. Recent efforts carried out to optimize patient dose during CT examination by using special imaging techniques with consideration of patient characteristics [20,21]. Indeed, the purpose of the present study was to investigate how the introduction of MDCT scanners and patient-size-dependent imaging protocols have affected patient doses and propose a simple method to predict an estimation of the organ and effective doses by using BMI and mAeff.

\section{Materials and Methods}

\section{Standardized phantoms and the derivation of DLP values}

Console-displayed DLP values are estimates based on standardized dose measurements (weighted CT dose index, CTDIw) performed by the manufacturer on each scanner model using polymethyl methacrylate cylinder phantoms of standardized sizes, usually a $16 \mathrm{~cm}$ diameter head phantom and a larger $32 \mathrm{~cm}$ body or torso phantom. These phantom sizes, are based on an average-size adult patient. The scanner software uses these data in association with the technical parameters and length of coverage prescribed by the technologist for an individual scan to generate a DLP estimate [22]. Current CT scans will calculate the dosimetry data of each scan, including the CT dose index (CTDIVOL with the unit mGy) and crated dose per unit length [DLP with the unit mGy.cm] for each scan that the use of these data is a common method to estimate the effective dose. Referring to the reported dose that will be presented by commercial scanners by the end of the CT scan process, the DLP, mAeff and other parameters needed to calculate the dose, can be received. By entering this information and the scan information into ImPACT program, the amount of dose can be calculated.

\section{CT scan}

Multi-slice scanner is made of Germany's Siemens [Siemens somatom sensation 64-slice CT scanner] was used in the study.
The scan conditions which are used in this study for abdominal and pelvicare included: $\mathrm{mAs}=150, \mathrm{kv}=120$, pitch $=1$ and collimation $=10 \mathrm{~mm}$.

\section{Report weighting factors}

ICRP is declared in its103 report in 2007, a new weighting factor of different tissues [23]. The main change in this Report compared to Report No. 60, was for gonadal tissue and the breast. The breast weighting factor is increased from 0.05 to 0.12 and Gonad weighting factor is reduced from 0.12 to 0.08 [24].

\section{Impact software}

Doses to organs and effective dose for adult patients that underwent the abdomen and pelvic examination was calculated by ImPACT software version 1.0.4. ImPACT CT Patient Dosimetry Calculator is a computer application in which data sets of Monte Carlo will be used for dose calculation in the CT examinations [25]. Although the calculations are usually used for tissues and effective dose, but the difference in the size of the patient [or $\mathrm{BMI}]$ is not considered.

\section{Effective and organ dose calculation}

52 adult patients that performed CT scan of the abdomen and pelvic area were examined. To calculate the dose of these people through the ImPACT software, the information about the exposure conditions such as $\mathrm{kVp}, \mathrm{mAs}$, pitch, collimation, as well as scan output parameters including DLP and mAeff that is reported at the end of the scan by the scanner, will be notedon a form. By entering the scanning conditions and output of the scanner in ImPACT software, effective and organ dose of patients were calculated. In addition, height and weight of the patients were measured. A link between effective dose, mAeff and DLP is reviewed compare to BMI.

\section{Results}

To evaluate the scanners' adaptability across a different patient's size, dose-patient size dependency and noise patient size dependency were linearized. For this work, the CTDIvol and related DLP were used as a dose index as a scanner-independent metric. The intrinsic variability of the noise values [mean, min and max] across different slices in the mentioned scanner involved in this study were calculated for abdomen-pelvic protocol equal to [3.87: 2.52; 8.94] respectively. Figure 1 shows the 3D-fit plot of dose versus patient effective diameter and noise. The vertical and horizontal axes represent Noise and CTD Ivol respectively, while the third axis represents the patient effective diameter. The fit was performed with a 1st degree linear function and the RMSE values are obtained equal to 0.031 . The effective and organ dose for 52 adult patients that performed abdominal and pelvic CT scan were calculated and the relation between BMI with scanned outcome parameters were reviewed. Figure 2 shows the organs dose during of the abdomen and pelvic CT examination which is computed by ImPACT software. The average effective dose of patients was calculated equal to $6 \mathrm{mSv}$. 


\section{Current Trends in Clinical \& Medical Imaging}

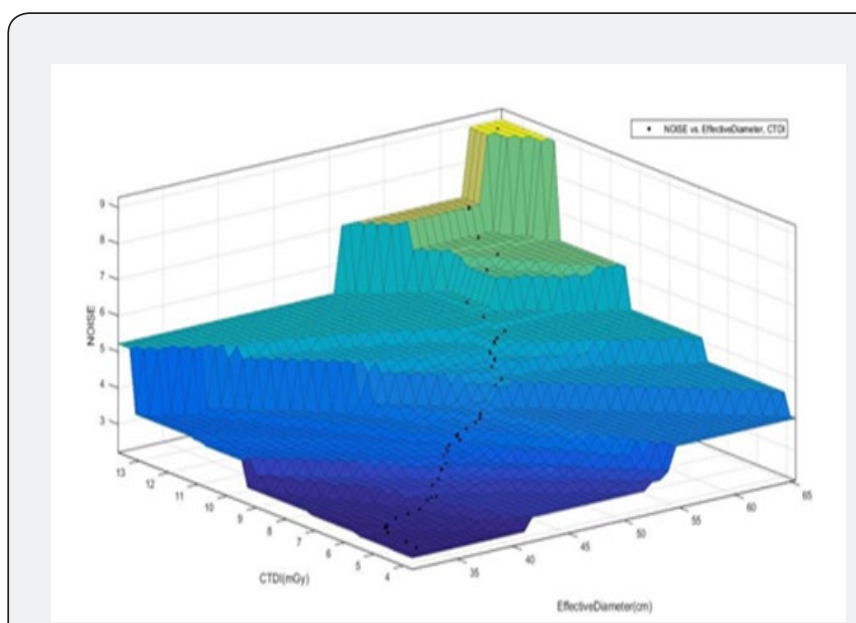

Figure 1: 3D-fit plot of dose versus patient effective diameter and noise

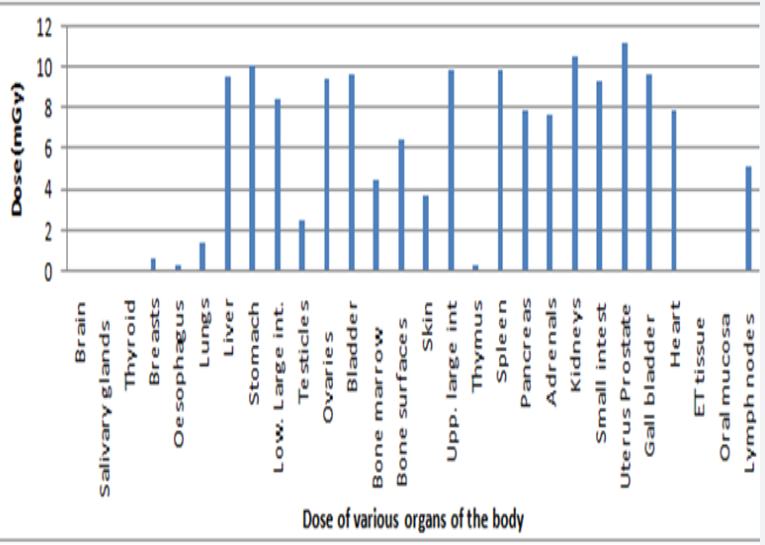

Figure 2: Dose of various organs of the body in a CT scan of the abdomen and pelvic computed by ImPACT

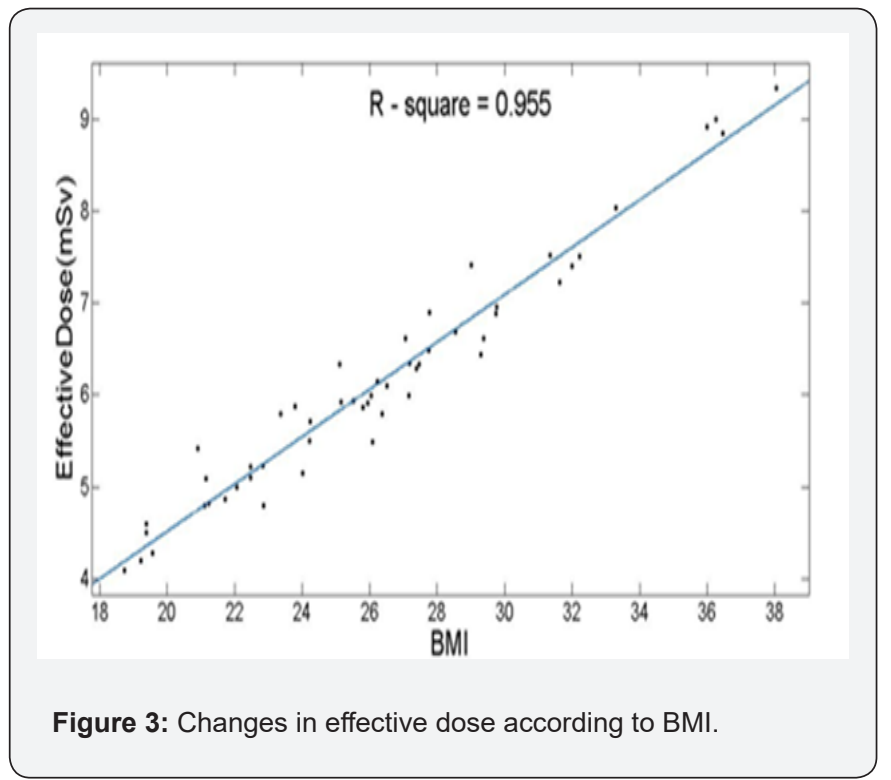

The relation between calculated effective dose, mAeff and DLP according to BMI was determined and the results are shown in Figures 2 to 5 respectively. As shown in Figure 3, the effective dose increases with increasing BMI that there is a linear relation with increasing BMI. An empirical equation is obtained for effective dose according to BMI and it is as follows:

Effective Dose $[\mathrm{mSv}]=0.257 \mathrm{BMI}-0.637$ [1]

As shown in Figure 4, the mAeff changes according to BMI that there is a linear relation with increasing BMI. An empirical equation is obtained for effective dose according to $\mathrm{BMI}$ and it is as follows:

mAeff $[\mathrm{mGy} . \mathrm{cm}]=4.73$ BMI $-19.81 \quad[2]$

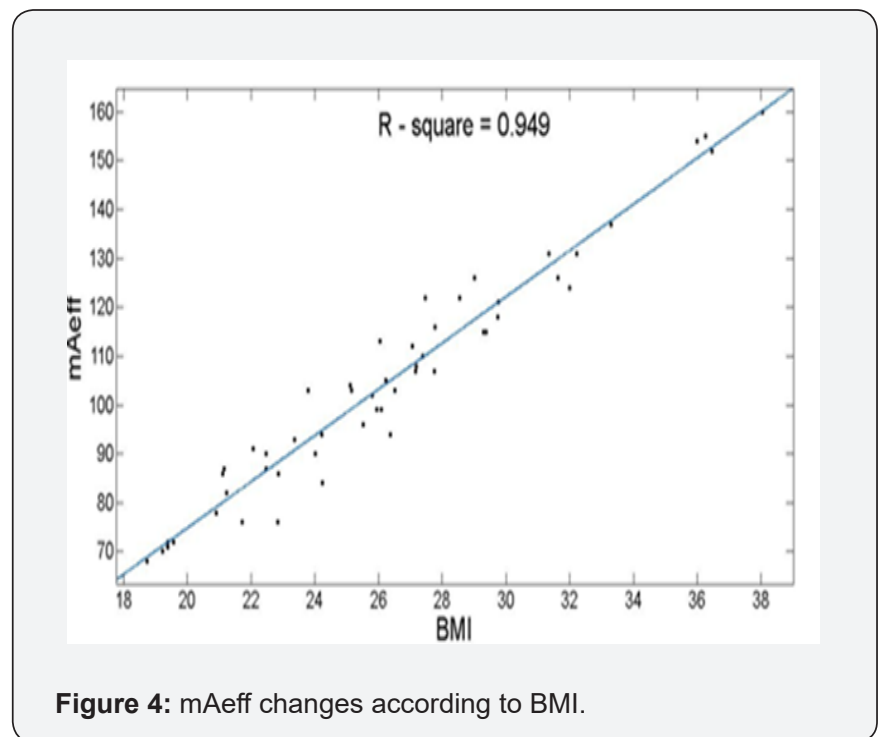

As shown in Figure 5, the DLP changes according to BMI that there is a linear relation with increasing BMI. An empirical equation is obtained for effective dose according to $\mathrm{BMI}$ and it is as follows:

DLP $[\mathrm{mGy.cm}]=17.17$ BMI $-56.36 \quad[3]$

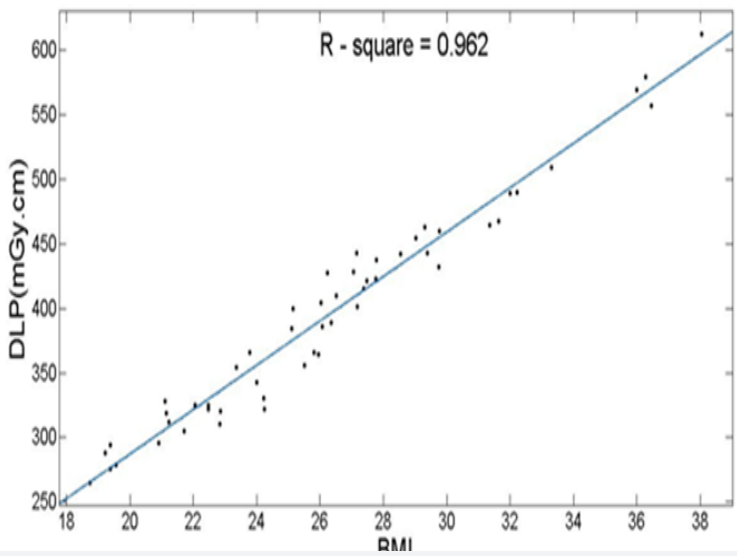

Figure 5: DLP changes according to BMI. 
The relation between calculated effective dose, mAeff and DLP according to BMI was obtained and the result is presented as an empirical equation 4 . The equation was obtained using multiregression in SPSS version 2015 environment. The variance inflation factor [VIF] was calculated and it show that there is multi-co linearity between effective doses with three other parameters. For all parameters, the VIF is calculated greater than 10 and tolerance is obtained less than 0.1 . The results are presented in Table 1 and the results of ridge regression are presented in Table 2.

Effective dose $=0.136+[0.097 \times \mathrm{BMI}]+[0.018 \times \mathrm{MAeff}]+$ [0.003×DLP] [4]

Table 1: calculated VIF and Tolerance for different parameters

\begin{tabular}{|c|c|c|}
\hline Variable & VIF & Tolerance \\
\hline BMI & 29.905 & 0.033 \\
\hline DLP & 38.098 & 0.026 \\
\hline mAeff & 28.483 & 0.035 \\
\hline
\end{tabular}

Table 2: Results of ridge regression for different parameters

\begin{tabular}{|c|c|c|c|c|}
\hline Variable & Beta & $\begin{array}{c}\text { Standardized } \\
\text { beta }\end{array}$ & SE & P-value \\
\hline intercept & 0.136 & - & - & - \\
\hline BMI & 0.097 & 3.275 & 0.321 & $<0.001$ \\
\hline mAeff & 0.018 & 3.051 & 0.325 & $<0.001$ \\
\hline DLP & 0.003 & 2.286 & 0.299 & $<0.001$ \\
\hline
\end{tabular}

\section{Discussion}

The organs and effective doses of the abdomen - pelvic examination in CT was calculated based on BMI. In 2015 Huda is investigated the effective dose for routine head and abdominal/pelvic CT examinations. Head and abdomen of patients were modeled as a mass-equivalent cylinder of water. The corresponding abdominal CT effective doses ranged from $6.3 \mathrm{mSv}$ in adults which is close to the result of current study [26]. Another study is reported the effective dose in abdomen/ pelvic examination which is equal to $5.01 \pm$ [2.34 \%] $\mathrm{mSv}$ by using MOSFET dosimetry and $5.56 \mathrm{mSv}$ with the DLP method [27].

Figure 3 shows the appropriate linear relationship between BMI and effective dose. As Figure 3 shows that increasing in BMI, increases the effective dose which is correspond with the results of other studies [28,29]. But should be mentioned that, the BMI determines the $\mathrm{mA}$ which is affected on CT dose index and DLP. Figure 4 \& 5 shows the linear relationship between effective $\mathrm{mA}$ [mAeff] and DLP based on body mass index. The results show that the patient body mass index is one of the important criteria in patient dosimetry and it should be considered. So this study proposes a height - weight model or BMI model which is using DLP for patient dose assessment. In a similar study, Israel proposed a model to predict the CT dose index [CTDI] based on the weight that comply with the R2 $=0.82$ [30], while the model of this study predict effective dose by using DLP with the R2 = 0.95 . The results of this study described a model based on height and weight $[\mathrm{BMI}]$ which is more accurate and complete model to predict the dose. The distribution of body weight per volume or length determines how the dose is changed. The DLP prediction models offer, the total dose in a CT scan based on the scan length. Thomas calculate effective dose in abdomen-pelvic examination for adults, by calculating DLP and using the related conversion factor to estimate the effective dose, $5.9 \mathrm{mSv}$ was achieved [31]. This study reported a linear relationship between increasing BMI and DLP with proper compliance and effective dose described, which is fully consistent with the results of Tartari [32].

\section{Conclusion}

The results of this study determine the relation between BMI and its impact on the body effective dose and define an equation for estimating body effective dose. According to the results of this study, Equation 1, might be a good alternative to estimate the effective dose according to BMI instead of ImPACT calculations for scanners and scanning conditions as well as the equation 4 , predict the effective dose by using the parameters of the CT system and BMI without being radiated on the patients.

\section{References}

1. McCollough CH, Guimarães L, Fletcher JG (2009) "In defense of body CT." AJR Am J Roentgenol 193(1): 28-39.

2. Janbabanezhad-Toori A, M Deevband, A Shabestani-Monfared, R Abdi M Nabahati (2016) "Pediatric dose assessment in common CT examination towards establishment of related regional DRL in Mazandaran, Iran." IJRR 14(3): 251-256.

3. Mattison BJ, Nguyen GB, Januzis N, Lowry C, Yoshizumi TT (2016) "A Novel Approach For Effective Dose Measurements In Dual-Energy Ct." Radiat Prot Dosimetry 172(4): 416-421

4. Rubinshtein R, Halon DA, Gaspar T, Jaffe R, Karkabi B, et al. (2007) "Usefulness of 64-slice cardiac computed tomographic angiography for diagnosing acute coronary syndromes and predicting clinical outcome in emergency department patients with chest pain of uncertain origin." Circulation 115(13): 1762-1768.

5. Council NR (1998) Health effects of exposure to low levels of ionizing radiations: time for reassessment?, National Academies Press.

6. Amis ES, Butler PF, Applegate KE, Birnbaum SB, Brateman LF, et al. (2007) "American College of Radiology white paper on radiation dose in medicine." J Am Coll Radiol 4(5): 272-284.

7. Nijhof WH, Baltussen EJ, Kant IM, Jager GJ, Slump CH, et al. (2016) "Low-dose CT angiography of the abdominal aorta and reduced contrast medium volume: Assessment of image quality and radiation dose." Clin Radiol 71(1): 64-73.

8. Brix G, Nagel HD, Stamm G, Veit R, Lechel U, et al. (2003) "Radiation exposure in multi-slice versus single-slice spiral CT: results of a nationwide survey." Eur Radiol 13(8): 1979-1991.

9. Mettler FA, Wiest PW, Locken JA, Kelsey CA (2000) “CT scanning: patterns of use and dose." J Radiol Prot 20(4): 353-359.

10. Brenner DJ, Hall EJ (2007) "Computed tomography-an increasing source of radiation exposure." N Engl J Med 357(22): 2277-2284.

11. Task Group on Control of Radiation Dose in Computed Tomography (2000) "Managing patient dose in computed tomography. A report of the International Commission on Radiological Protection." Ann ICRP 30(4): 7-45. 


\section{Current Trends in Clinical \& Medical Imaging}

12. Berrington de González A, Mahesh M, Kim KP, Bhargavan M, Lewis R, et al. (2009) "Projected cancer risks from computed tomographic scans performed in the United States in 2007." Arch Intern Med 169(22): 2071-2077.

13. Mettler FA Jr, Huda W, Yoshizumi TT, Mahesh M (2008) "Effective doses in radiology and diagnostic nuclear medicine: a catalog." Radiology 248(1): 254-263.

14. McCollough CH, Schueler BA (2000) "Calculation of effective dose." Med Phys 27(5): 828-837.

15. Commission IE (2002) Particular requirements for the safety of X-ray equipment for computed tomography: amendment I, 2002-09, International Electro-technical Commission: Geneva, Switzerland.

16. Paydar RA, Takavar M, Kardan A, Babakhani M, Deevband, et al. (2012) "Patient effective dose evaluation for chest X-ray examination in three digital radiography centers." Iran J Radiat Res 10(3-4): 139-143.

17. Shrimpton PC, BF Wall (2009) "Effective dose and dose-length product in CT." Radiology 250(2): 604-605.

18. Ogden K, W Huda (2009) "SU-FF-I-67: Converting CT Dose Length Product (DLP) to Kerma Area Product (KAP)." Med Phys 36(6): 24502450 .

19. Shrimpton PC, Hillier MC, Lewis MA, Dunn M (2006) "National survey of doses from CT in the UK: 2003." Br J Radiol 79(948): 968-980.

20. Huda W, Bushong SC (2001). "In x-ray computed tomography, technique factors should be selected appropriate to patient size.” Med Phys 28(8): 1543-1545.

21. Huda W, Scalzetti EM, Levin G (2000) “Technique factors and image quality as functions of patient weight at abdominal CT." Radiology 217(2): 430-435.

22. Safety C (2008) Efficacy: A Broad Perspective. 2004 CT quality criteria. Appendix A-MSCT dosimetry, guidelines on radiation dose to the patient.
23. Valentin J (2007) The 2007 recommendations of the international commission on radiological protection, Elsevier Oxford.

24. Thorne M (1992) 1990 recommendations of the international commission on radiological protection: Ann. ICRP 21 (1-3), 1991.

25. ImPACT, http://www.impactscan.org/ctdosimetry.htm.

26. Huda W, Tipnis SV (2015) “Doses metrics and patient age in CT.” Radiat Prot Dosimetry 168(3): 374-380.

27. Mattison BJ, Nguyen GB, Januzis N, Lowry C, Yoshizumi TT (2016) "A Novel Approach For Effective Dose Measurements In Dual-Energy CT." Radiat Prot Dosimetry 172(4): 416-421.

28. Feuchtner GM, Jodocy D, Klauser A, Haberfellner B, Aglan I, et al. (2010) "Radiation dose reduction by using $100-\mathrm{kV}$ tube voltage in cardiac 64-slice computed tomography: a comparative study." Eur J Radiol 75(1): e51-e56.

29. Kalra MK, Maher MM, Toth TL, Hamberg LM, Blake MA, et al. (2004) "Strategies for CT radiation dose optimization." Radiology 230(3): 619628.

30. Israel GM, Cicchiello L, Brink J, Huda W (2010) "Patient size and radiation exposure in thoracic, pelvic, and abdominal CT examinations performed with automatic exposure control." AJR Am J Roentgenol 195(6): 1342-1346.

31. Thomas KE, B Wang (2008) "Age-specific effective doses for pediatric MSCT examinations at a large children's hospital using DLP conversion coefficients: a simple estimation method." Pediatr Radiol 38(6): 645656.

32. Tartari S, Rizzati R, Righi R, Deledda A, Terrani S, et al. (2010) "Lowdose unenhanced CT protocols according to individual body size for evaluating suspected renal colic: cumulative radiation exposures." Radiol Med 115(1): 105-114.

\section{Your next submission with Juniper Publishers} will reach you the below assets

- Quality Editorial service

- Swift Peer Review

- Reprints availability

- E-prints Service

- Manuscript Podcast for convenient understanding

- Global attainment for your research

- Manuscript accessibility in different formats

( Pdf, E-pub, Full Text, Audio)

- Unceasing customer service

Track the below URL for one-step submission https://juniperpublishers.com/online-submission.php 